\title{
Vanadium Oxide Monolayer Catalysts
}

\author{
The Vapor-Phase Oxidation of Methanol \\ Fred Roozeboom, ${ }^{1}$ Peter D. Cordingley, and Paul J. Gellings \\ Department of Chemical Technology, Twente University of Technology, P.O. Box 217, 7500 AE Enschede, \\ The Netherlands
}

Received July 14, 1980

\begin{abstract}
The oxidation of methanol over vanadium oxide, unsupported and applied as a monolayer on $\gamma$ $\mathrm{Al}_{2} \mathrm{O}_{3}, \mathrm{CeO}_{2}, \mathrm{TiO}_{2}$, and $\mathrm{ZrO}_{2}$, was studied between 100 and $400^{\circ} \mathrm{C}$ in a continuous-flow reactor. At temperatures from 150 to about $250^{\circ} \mathrm{C}$ two main reactions take place, $(a)$ dehydration of methanol to dimethyl ether and $(b)$ partial oxidation to formaldehyde. A very slight direct oxidation to $\mathrm{CO}_{z}$ proceeds simultaneously. At higher temperatures two further reactions take place, i.e., (c) consecutive oxidation of the ether and/or formaldehyde to $\mathrm{CO}$ and $(d)$ consecutive oxidation of $\mathrm{CO}$ to $\mathrm{CO}_{2}$. Selectivity to formaldehyde increased with decreasing reducibility of the catalyst, which in turn was a function of the catalyst-support interactions. Since the reducibility of $V(V)$ has been shown to be related to the charge/radius ratio of the cation of the carrier, the selectivity to formaldehyde is also determined by this ratio.
\end{abstract}

\section{INTRODUCTION}

The selective oxidation of methanol to formaldehyde has been studied by many authors $(1-2 l)$, mainly because of its importance in the industrial production of formaldehyde (U.S. production in 1977: 2.8 $\times 10^{6}$ tons). $(I)$. The process was at first based on a silver oxide catalyst, but this was later replaced by $\mathrm{MoO}_{3}-\mathrm{Fe}_{2}\left(\mathrm{MoO}_{4}\right)_{3}$ which had high selectivity to formaldehyde (2). The present status of research on the mixed Fe-Mo catalyst has been reviewed by Pernicone (3).

As a sequel to the study of the oxidation activity of vanadium oxide monolayer catalysts $(22-25)$ the activity and selectivity of these catalysts for the methanol oxidation have been studied. This paper deals with the catalytic behavior towards methanol oxidation on vanadium oxide, unsupported and supported as a monolayer (or monomolecular dispersion) on $\gamma-\mathrm{Al}_{2} \mathrm{O}_{3}, \mathrm{CeO}_{2}, \mathrm{TiO}_{2}$, and $\mathrm{ZrO}_{2}$. In particular the possible

\footnotetext{
${ }^{1}$ Present address: Exxon Research and Development Laboratories, P.O. Box 2226, Baton Rouge, La. 70821.
}

influence of the carrier oxides on the properties of the monolayer was investigated.

\section{EXPERIMENTAL}

Materials. Unsupported $\mathrm{V}_{2} \mathrm{O}_{5}$ was prepared from $\mathrm{NH}_{4} \mathrm{VO}_{3}$ (Merck, analytical grade) by thermal decomposition at $600 \mathrm{~K}$ for $2 \mathrm{~h}$ in a stream of air. The supports, $\gamma$ $\mathrm{Al}_{2} \mathrm{O}_{3}, \mathrm{CeO}_{2}, \mathrm{TiO}_{2}$, and $\mathrm{ZrO}_{2}$ were described earlier $(22,23)$. Helium and oxygen gas (Loosco, Amsterdam) were dried by BDH molecular sieve type 4A. Helium was further deoxygenated by BTS catalyst R-311 (BASF, Germany). Methanol was from Merck, analytical grade. For calibration of the gas-chromatographic analyses, $\mathrm{CO}$ and $\mathrm{CO}_{2}$ gas (both Loosco, Amsterdam) a formaldehyde solution (Baker, analytical grade), and dimethyl ether (Matheson) were used.

Catalyst preparation. Supported vanadium oxide catalysts were prepared by passing a freshly prepared aqueous solution of $\mathrm{NH}_{4} \mathrm{VO}_{3}$ (1 wt\%), acidified to $\mathrm{pH}=4$, through a bed of support particles (0.3-0.6 $\mathrm{mm}$ diameter). The catalysts were dried at $383 \mathrm{~K}(17 \mathrm{~h})$ and calcined at $723 \mathrm{~K}(2 \mathrm{~h})$. For further details see Part 1 of this series (22). 
$X$-ray fluorescence. The vanadium content of the catalysts was determined by Xray fluorescence with a Philips $1410 \mathrm{X}$-ray spectrometer (26).

BET surface area measurements. Surface areas of the catalysts were determined as described previously (22).

Apparatus. Figure 1 shows the flow diagram of the apparatus used for methanol oxidation studies. Compressed helium and oxygen from cylinders were separately passed through purifying tubes. Both gases were dried with molecular sieves and helium was deoxygenated with a BTS catalyst. The gases passed through separate pressure controllers (PC) and pressure indicators (PI), then through flow controllers (FC) and indicators (FI) before mixing. Methanol was introduced by bubbling the $\mathrm{He}-\mathrm{O}_{2}$ mixture through a glass saturator filled with methanol. The saturator was immersed in a thermostat, which was usually kept at $286 \mathrm{~K}$. Behind the saturator all stainless-steel tubing was heated to prevent condensation (dotted tubings in Fig. 1).

The reactor was a quartz tube $(0.5 \mathrm{~cm}$ inner diameter and about $40 \mathrm{~cm}$ long) placed concentrically in a quartz tube of 1.0 $\mathrm{cm}$ inner diameter, on the outside of which an electric heating wire was wound. A fritted quartz disc in the reactor tube supported the catalyst bed. For all runs $0.2 \mathrm{~g}$ of catalyst $(0.3-0.6 \mathrm{~mm}$ gain diameter) was used, mixed with $0.2 \mathrm{~g}$ of (inert) quartz grains of similar size, in order to minimize exothermic effects. A quartz wool plug was tamped down on top of the catalyst to prevent fluidizing of the bed or loss of the catalyst. The catalyst bed height was usually about $1 \mathrm{~cm}$. The reactor temperature was controlled by a chromel-alumel thermocouple (located with its tip in the catalyst bed) connected to a temperature controller. Manometers were placed before and after the reactor. A bypass system with a restrictive valve could be used to circumvent the reactor with equal restriction.

The feed gas consisted of approximately $72 \mathrm{vol} \% \mathrm{He}, 24 \mathrm{vol} \% \mathrm{O}_{2}$, and $4 \mathrm{vol} \%$ methanol vapor. The total gas flow usually amounted to $40 \mathrm{ml}$ (NTP) $\cdot \mathrm{min}^{-1}$.

Analyses were carried out with a Varian 3700 modular dual-column gas chromatograph connected to a chart recorder and an integrator (Infotronics). The columns were of stainless steel, each $1 \mathrm{~m}$ in length and $\frac{1}{8}$ in. outer diameter, filled with $60-80$ mesh carbosphere support. Semiautomatic sampling was performed with an eight-way Carle microvolume switching valve with an analysis loop volume of $0.5 \mathrm{ml}$, which was placed in a valve oven kept at $450 \mathrm{~K}$. The accuracy of this analytical procedure on the basis of carbon material balance was proven to be within $10 \%$. Reaction temperatures were chosen in a random order rather than in a rising or falling order. In these results only the temperature region in

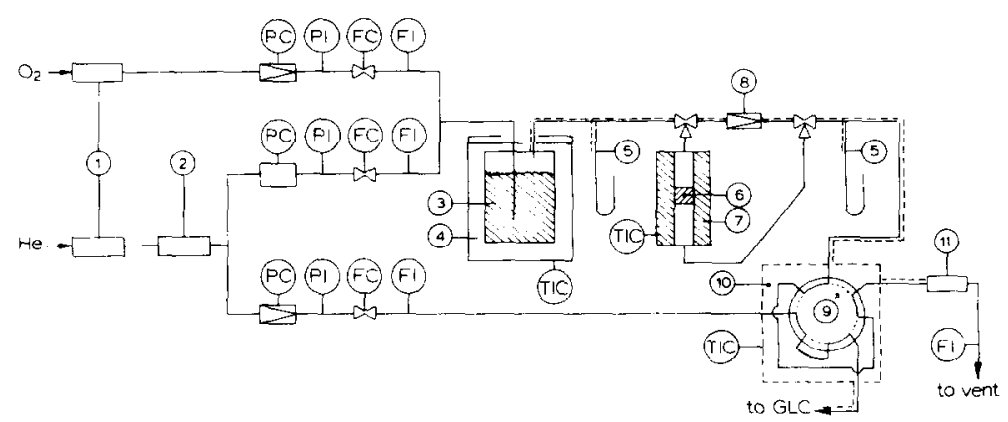

FIG. 1. Flow diagram of apparatus for methanol oxidation. $1=$ tube with molecular sieve; $2=$ tube with BTS catalyst R-3-11;3= vaporizer filled with pure methanol; $4=$ thermostat; $5=$ mercury manometers; $6=$ reactor tube; $7=$ tubular furnace; $8=$ restriction valve; $9=$ eight-way valve; $10=$ valve oven; $11=$ condenser and $\ldots---=$ heated tubings. 
which noticeable activity is observed, is considered. Therefore it was decided not to recalculate these activities to specific values based on the only slightly differing $V$ contents. For every temperature the average of several steady-state activity measurements was calculated when the separate values did not differ by more than about $15 \%$. In general, a steady state was reached within $15 \mathrm{~min}$ and at each temperature at least three measurements were performed. Within a total time of $48 \mathrm{~h}$ for a complete series of measurements no significant change in activity was observed.

\section{RESULTS}

The physicochemical properties and data of the supported and unsupported vanadium oxide catalysts were reported earlier (22-24).

The following catalysts, described and tested for $\mathrm{CO}$ oxidation (25), were tested here for methanol oxidation: unsupported $\mathrm{V}_{2} \mathrm{O}_{5}$ (prepared from $\mathrm{NH}_{4} \mathrm{VO}_{3}$ ), $\mathrm{V} / \gamma-\mathrm{Al}_{2} \mathrm{O}_{3}$, $\mathrm{V} / \mathrm{CeO}_{2}, \mathrm{~V} / \mathrm{TiO}_{2}, \mathrm{~V} / \mathrm{ZrO}_{2}$ (where $\mathrm{V}$ indicates vanadium oxide monolayer) as well as the pure supports.

Unsupported $\mathrm{V}_{2} \mathrm{O}_{5}$. Catalytic activity and selectivities of pure $\mathrm{V}_{2} \mathrm{O}_{5}$ are presented in Fig. 2. Formaldehyde is the main product up to $260^{\circ} \mathrm{C}$, together with some dimethyl

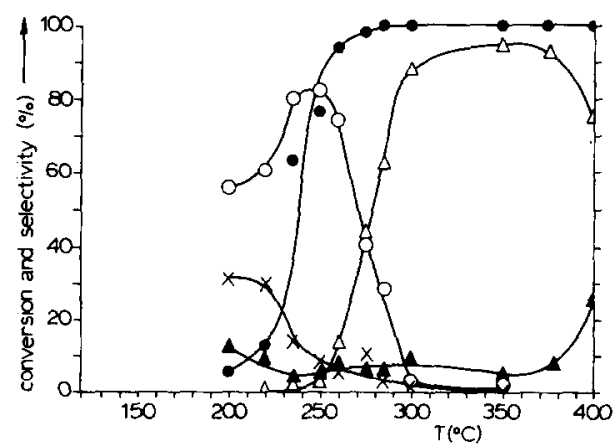

FIG. 2. Methanol oxidation over unsupported $\mathrm{V}_{2} \mathrm{O}_{5}$ $\left(S_{\mathrm{BET}}=9.5 \mathrm{~m}^{2} \mathrm{~g}^{-1}\right)$. Total conversion (moles of methanol converted/moles of methanol fed) $\times 100 \%$; $x$, selectivity to dimethyl ether; $O$, selectivity to formaldehyde; $\triangle$, selectivity to $C O$, and $\Delta$, selectivity to $\mathrm{CO}_{2}$. Selectivities: (moles of methanol converted to product $i /$ moles of methanol converted) $\times 100 \%$. ether and small amounts of $\mathrm{CO}$ and $\mathrm{CO}_{2}$. At $260^{\circ} \mathrm{C}$ formaldehyde production rapidly decreases in favor of carbon monoxide formation. From about $380^{\circ} \mathrm{C}$ the formation of $\mathrm{CO}$ decreases and that of $\mathrm{CO}_{2}$ increases.

$\gamma-\mathrm{Al}_{2} \mathrm{O}_{3}$ and $\mathrm{V} / \gamma-\mathrm{Al}_{2} \mathrm{O}_{3}$. Figure 3 shows the activiy and selectivity patterns of $\mathrm{V} / \gamma$ $\mathrm{Al}_{2} \mathrm{O}_{3}$ and pure $\gamma-\mathrm{Al}_{2} \mathrm{O}_{3}$. The pure carrier shows a high activity for dehydration of the methanol to dimethyl ether up to $330^{\circ} \mathrm{C}$. At higher temperatures activity for $\mathrm{CO}$ and $\mathrm{CO}_{2}$ becomes predominant. $\mathrm{V} / \gamma-\mathrm{Al}_{2} \mathrm{O}_{3}$ shows up to $220^{\circ} \mathrm{C}$ high activity and selectivity to formaldehyde and only a slight selectivity to dimethyl ether. From $220^{\circ} \mathrm{C}$ formaldehyde production decreases, again in favor of a high activity and selectivity of $\mathrm{CO}$ up to $380^{\circ} \mathrm{C}$. Above this temperature formation of $\mathrm{CO}$ drops and that of $\mathrm{CO}_{2}$ rises.

$\mathrm{CeO}_{2}$ and $\mathrm{V} / \mathrm{CeO}$. Pure $\mathrm{CeO}_{2}$ (Fig. 4) shows high selectivity to $\mathrm{CO}$ and $\mathrm{CO}_{2}$ and no selectivity to other products. When a

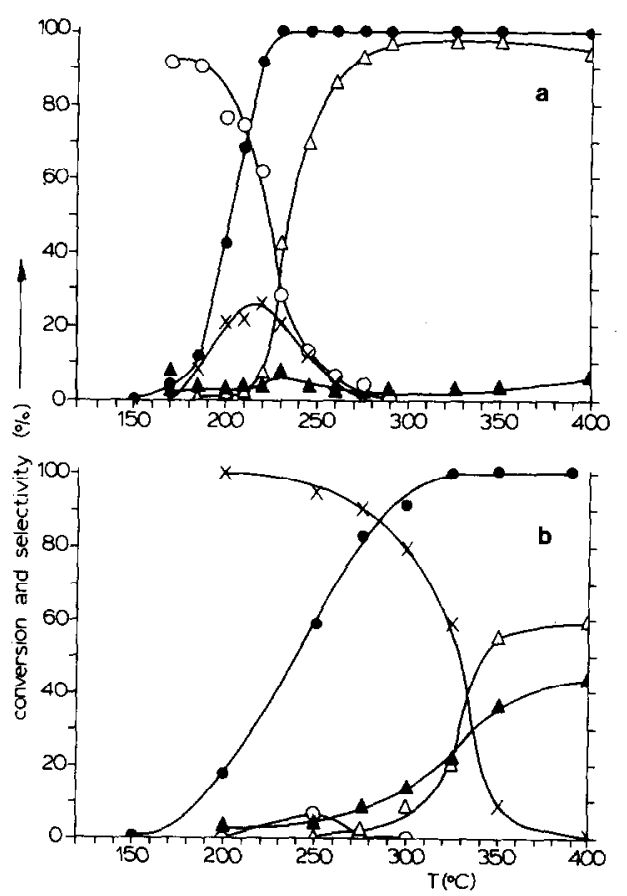

FIG. 3. Methanol oxidation over (a) $\mathrm{V} / \gamma-\mathrm{Al}_{2} \mathrm{O}_{3}(80$ $\left.\mathrm{m}^{2} \mathrm{~g}^{-1}, 6.8 \% \mathrm{~V}\right)$ and (b) $\gamma-\mathrm{Al}_{2} \mathrm{O}_{3}\left(80 \mathrm{~m}^{2} \mathrm{~g}^{-1}\right)$. For symbols see Fig. 2. 


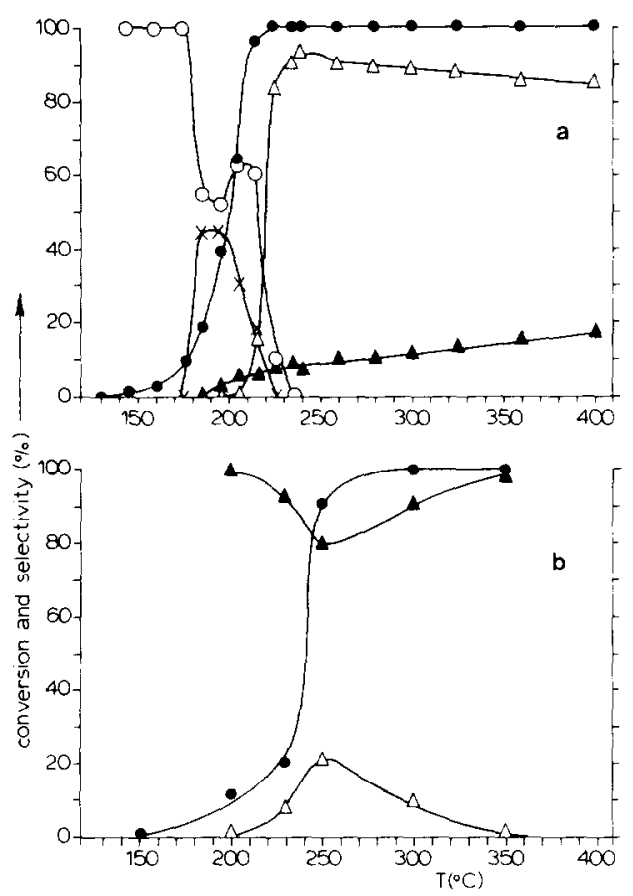

FIG. 4. Methanol oxidation over (a) $\mathrm{V} / \mathrm{CeO}_{2}\left(48 \mathrm{~m}^{2}\right.$ $\mathrm{g}^{-1}, 5.3 \% \mathrm{~V}$ ) and (b) $\mathrm{CeO}_{2}\left(48 \mathrm{~m}^{2} \mathrm{~g}^{-1}\right)$. For symbols see Fig. 2.

monolayer of vanadium oxide is applied onto the $\mathrm{CeO}_{2}$ the activity and selectivity patterns resemble those of $\mathrm{V} / \gamma-\mathrm{Al}_{2} \mathrm{O}_{3}$. At low temperatures up to $210^{\circ} \mathrm{C}$ there is high activity and selectivity to formaldehyde, together with some dimethyl ether. Above $220^{\circ} \mathrm{C}$ is the main product, whereas above $250^{\circ} \mathrm{C}$ gradually more $\mathrm{CO}_{2}$ is being formed at the expense of $\mathrm{CO}$.

$\mathrm{TiO}_{2}$ and $\mathrm{V} / \mathrm{TiO}_{2}$. At temperatures up to about $300^{\circ} \mathrm{C}$ the pure $\mathrm{TiO}_{2}$ carrier (see Fig. 5) shows a minor dimethyl ether production together with a highly selective formation of formaldehyde. Above $300^{\circ} \mathrm{C}$ this selectivity falls very fast and total oxidation predominates, first to $\mathrm{CO}$ and at higher temperatures to $\mathrm{CO}_{2}$.

The activity and selectivity patterns of $\mathrm{V} / \mathrm{TiO}_{2}$ resemble those of pure $\mathrm{V}_{2} \mathrm{O}_{5}$ and pure $\mathrm{TiO}_{2}$, as regards the sequence of selectivities. However, the activity of the monolayer catalyst is larger, i.e., the temperature at which a comparable conversion occurs is significantly lower.

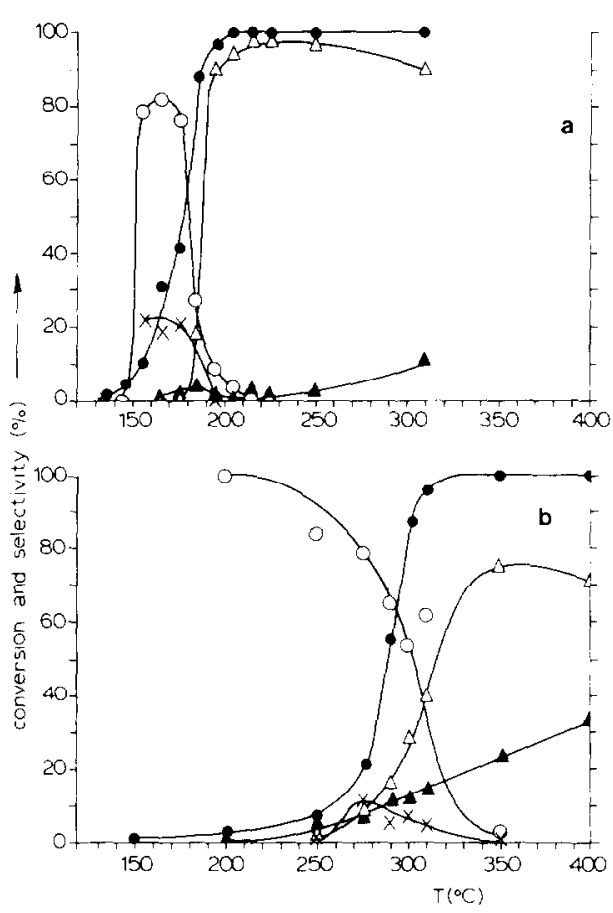

FIG. 5. Methanol oxidation over (a) $\mathrm{V} / \mathrm{TiO}_{2}\left(45 \mathrm{~m}^{2}\right.$ $\left.\mathrm{g}^{-1}, 1.7 \% \mathrm{~V}\right)$ and (b) $\mathrm{TiO}_{2}\left(45 \mathrm{~m}^{2} \mathrm{~g}^{-1}\right)$. For symbols see Fig. 2 .

The $\mathrm{V} / \mathrm{TiO}_{2}$ was checked for diffusion limitation effects by calculating the Thiele modulus, $m$. The rate constant at a gas flow rate of $20 \mathrm{ml} \cdot \mathrm{min}^{-1}$ was calculated to be approximately $0.035 \mathrm{sec}^{-1}$. The effective diffusion coefficient of the $\mathrm{TiO}_{2}$ used was determined to be $0.015 D_{\text {gas }}$ from measurements of $\mathrm{CO}_{2}$ diffusion. With a diffusion coefficient of $1 \mathrm{~cm}^{2} \cdot \mathrm{sec}^{-1}$ for methanol in He and a radius of $0.5 \mathrm{~mm}$ of the catalyst grains this gives $m=0.08$ indicating the complete absence of diffusion limitation.

$\mathrm{ZrO}_{2}$ and $\mathrm{V} / \mathrm{ZrO} \mathrm{O}_{2}$. Pure $\mathrm{ZrO}_{2}$ (Fig. 6) exhibits a high activity for the formation of $\mathrm{CO}$ and $\mathrm{CO}_{2}$, with at higher temperatures a decrease of $\mathrm{CO}$ formation in favor of $\mathrm{CO}_{2}$. Below $280^{\circ} \mathrm{C}$ some dimethyl ether was formed. No formation of formaldehyde was observed.

With $\mathrm{V} / \mathrm{ZrO}_{2}$, in the temperature range $150-175^{\circ} \mathrm{C}$, a moderate activity was observed with formaldehyde as the main product, as well as a considerable amount of dimethyl ether. Above $180^{\circ} \mathrm{C}$ the selec- 


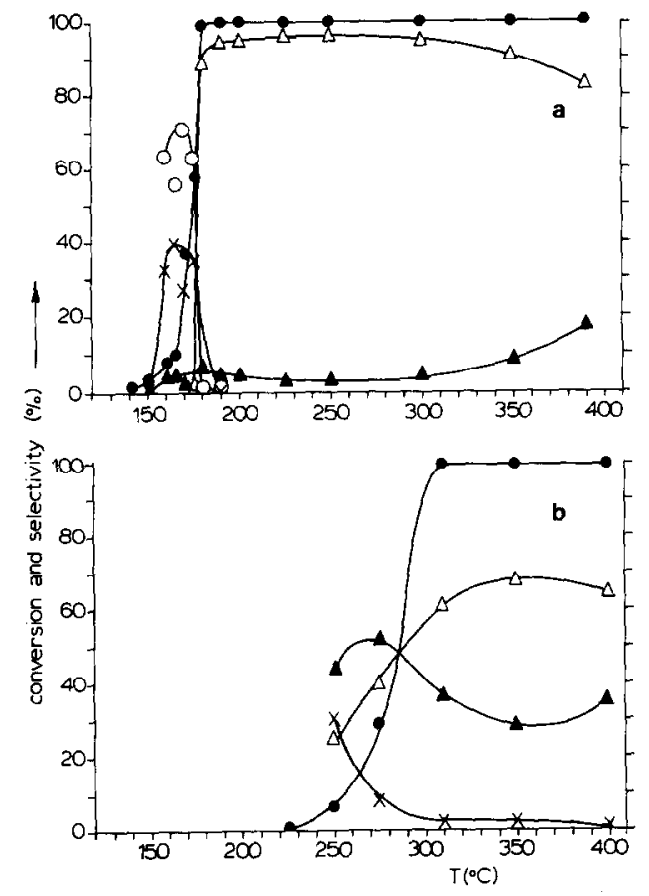

FIG. 6. Methanol oxidation over (a) $\mathrm{V} / \mathrm{ZrO}_{2}\left(107 \mathrm{~m}^{2}\right.$ $\left.\mathrm{g}^{-1}, 4.3 \% \mathrm{~V}\right)$ and $(\mathrm{b}) \mathrm{ZrO}_{2}\left(156 \mathrm{~m}^{2} \mathrm{~g}^{-1}\right)$. For symbols see Fig. 2.

tivity to formaldehyde decreases, whereas selectivity to $\mathrm{CO}$ increases, both very severely. Above $300-350^{\circ} \mathrm{C}$ more $\mathrm{CO}_{2}$ is gradually formed, the amount of $\mathrm{CO}$ proportionally diminishing.

In Figs. 2 and 6 one can distinguish two temperature regions of different $\mathrm{CO}_{2}$ production. In the temperature range of approximately $200-250^{\circ} \mathrm{C} \quad\left(150-200^{\circ} \mathrm{C}\right.$ for $\mathrm{V} / \mathrm{TiO}_{2}$ and $\left.\mathrm{V} / \mathrm{ZrO}_{2}\right) \mathrm{CO}_{2}$ is formed on every catalyst in a measurable (though in an absolute sense small) amount at a lower temperature than that at which $\mathrm{CO}$ is formed. At temperatures from $300-350^{\circ} \mathrm{C}$, $\mathrm{CO}_{2}$ is formed in large amounts at the expense of $\mathrm{CO}$.

\section{DISCUSSION}

All activity and selectivity patterns of the unsupported and supported vanadia catalysts show the same features. At low temperatures, the small selectivity to dimethyl ether rapidly decreases when the temperature is raised.

At the same, relatively low, temperatures a considerable amount of formaldehyde is formed, in all cases with higher activity and, at equal conversion, lower selectivity on the supported vanadia catalysts than on unsupported $\mathrm{V}_{2} \mathrm{O}_{5}$. Under mild conditions the two main reactions are $(a)$ dehydration of methanol to dimethyl ether and $(b)$ oxidation of methanol to formaldehyde and (slightly) to $\mathrm{CO}_{2}$. Under more severe circumstances (higher temperatures) two further reactions take place, namely, (c) consecutive oxidation of the formaldehyde to carbon monoxide and $(d)$ consecutive oxidation of $\mathrm{CO}$ and $\mathrm{CO}_{2}$. These reactions will be discussed separately.

\section{a. Dehydration of Methanol to Dimethyl Ether}

As can be seen from Figs. 2 to 6 dimethyl ether formation predominates with pure $\gamma$ $\mathrm{Al}_{2} \mathrm{O}_{3}$. This is in agreement with the literature, where primary alcohols have been reported to yield ethers upon dehydration on alumina $(27,28)$, especially under mild conditions (low temperatures and low contact times). When conditions are severe, ethers are reported to react further with alumina to produce the same final products which are obtained by reaction of the corresponding alcohols. Thus the decrease in selectivity to ether, presented in Figs. 2-6, may be explained in terms of consecutive oxidation. When $\gamma-\mathrm{Al}_{2} \mathrm{O}_{3}$, with its intrinsic high selectivity for dehydration, is covered with a monolayer of vanadium oxide the dehydrating activity decreases significantly (Fig. 3). This, combined with evidence presented previously $(22-24)$, is a further indication of the presence of a well-dispersed monolayer, covering the underlying $\gamma$ $\mathrm{Al}_{2} \mathrm{O}_{3}$. This is completely analogous to $\mathrm{V} / \mathrm{CeO}_{2}$, where the vanadia monolayer suppresses the activity for $\mathrm{CO}$ oxidation of the pure $\mathrm{CeO}_{2}$ carrier (25). 
b. Oxidation of Methanol to

Formaldehyde and Direct Oxidation to $\mathrm{CO}_{2}$

Methanol has been reported to be oxidized to formaldehyde presumably via an alcoholate bound to surface sites $(9,12) . \mathrm{Ai}$ (16) concludes these sites to be electron accepting (Lewis acidic) and proposes that they are anion vacancies. He further proposes electron-donating (Lewis-base) sites, suggested by him to be $\mathrm{O}^{2-}$ ions, to cause direct oxidation to $\mathrm{CO}_{2}$ under the same mild circumstances. Miyata $t$ al. (29) propose that $\mathrm{CO}_{2}$ is formed directly via a formate intermediate.

It may be seen from Figs. 2-6 that basic oxides like $\mathrm{ZrO}_{2}$ and in particular $\mathrm{CeO}_{2}$ indeed yield $\mathrm{CO}_{2}$ at temperatures as low as $200-250^{\circ} \mathrm{C}$. Here no selectivity to formaldehyde is observed. This may point to the predominance of basic sites over acidic sites on $\mathrm{ZrO}_{2}$ and $\mathrm{CeO}_{2}$, whereas on $\mathrm{TiO}_{2}$ sites with selectivity to formaldehyde predominate. On $\gamma-\mathrm{Al}_{2} \mathrm{O}_{3}$ an interpretation in terms of acid/base sites fails because of its high dehydration activity.

Ai's acid/base model suffers from the fact that it is difficult to quantify the number and strength of the basic and acidic sites and to identify these unambiguously. An interpretation in terms of acid/base properties of this type of oxidation seems to be somewhat doubtful. In the first place a metal iron like $\mathrm{Al}^{3+}$ is a relatively strong Lewis acid (i.e., electron acceptor) without, however, having oxidizing properties like $\mathrm{V}^{5+}$ or $\mathrm{V}^{4+}$. In the second place for metal ions with variable valency the acidbase properties change with the oxidation state, e.g., $\mathrm{Cr}^{6+}$ is strongly acidic and $\mathrm{Cr}^{3+}$ is basic.

The reducibility of an oxidic catalyst can be defined in several ways. For example, this can be expressed by the temperature where reduction by hydrogen begins in thermogravimetric (TG) experiments or where activity in $\mathrm{CO}$ oxidation starts to become measurable.
In both cases the order of reducibilities has been shown (25) to be

$$
\begin{aligned}
\mathrm{V}_{2} \mathrm{O}_{5}<V / \gamma-\mathrm{Al}_{2} \mathrm{O}_{3}< & \mathrm{V} / \mathrm{CeO}_{2} \\
& <\mathrm{V} / \mathrm{TiO}_{2}<\mathrm{V} / \mathrm{ZrO}_{2} .
\end{aligned}
$$

The onset temperatures of hydrogen reduction as determined by TG (25) are given in the second column of Table 1 . The table shows that the order of selectivity to formaldehyde is

$$
\begin{aligned}
\mathrm{V}_{2} \mathrm{O}_{5}>\mathrm{V} / \gamma-\mathrm{Al}_{2} \mathrm{O}_{3}>\mathrm{V} / \mathrm{CeO}_{2} \\
>\mathrm{V} / \mathrm{ZrO}_{2}<\mathrm{V} / \mathrm{TiO}_{2} .
\end{aligned}
$$

With $\mathrm{V} / \mathrm{TiO}_{2}$ as an exception it can be concluded that selectivity increases when reducibility decreases. This observation is in agreement with the findings of Sachtler $e t$ al. (30) who stated that activity and reducibility run parallel (as shown in this case by the parallelism of the reduction temperature and the temperature at $50 \%$ conversion) and that selectivity and reducibility (i.e., ease of removal of oygen) run antiparallel.

Also Boreskov (31) concluded that an increase in the energy of oxygen bonding (i.e., a decrease in ease of oxygen removal) reduces the rate of methanol oxidation on oxidic catalysts and increases the selectivity to formaldehyde.

The results of a study (24) on the reducibility of vanadium oxide monolayer catalysts, conducted by TPR, leads to the assumption that the reducibility of a catalyst is. mainly influenced by catalyst-support interactions. These interactions can be related to the parameter $z / a$, i.e., the ratio of the carrier cation charge to the sum of ionic radii of carrier cation and oxide anion $(22,32,33)$. From Table 1 it can be seen that, except for $\mathrm{V} / \mathrm{TiO}_{2}$, the parallelism between reducibility and $z / a$ on the one hand and the antiparallelism between selectivity and $z / a$ on the other hand holds rather well.

$\mathrm{V} / \mathrm{TiO}_{2}$ exhibits a selectivity to formaldehyde which is larger and a reducibility which is lower than expected on the basis of its $z / a$ parameter. This irregularity may 
TABLE 1

Results on Methanol Oxidation

\begin{tabular}{lcccc}
\hline Catalyst & $\begin{array}{c}\text { Onset tempera- } \\
\text { ture of } \mathrm{H}_{2} \\
\text { reduction }(25) \\
\left({ }^{\circ} \mathrm{C}\right)\end{array}$ & $\begin{array}{c}\text { Reaction } \\
\text { temperature } \\
\text { at } 50 \% \text { total } \\
\text { conversion } \\
\left({ }^{\circ} \mathrm{C}\right)\end{array}$ & $\begin{array}{c}\text { Selectivity to } \\
\text { formaldehyde } \\
\text { at } 50 \% \text { total } \\
\text { conversion } \\
(\%)\end{array}$ & $\begin{array}{c}z / a \text { of carrier } \\
\text { cation }(22)\end{array}$ \\
\hline $\mathrm{V}_{2} \mathrm{O}_{5}$ & & 240 & 82 & -55 \\
$\mathrm{~V} / \gamma-\mathrm{Al}_{2} \mathrm{O}_{3}$ & 460 & 203 & 81 & 1.55 \\
$\mathrm{~V} / \mathrm{CeO}_{2}$ & 360 & 200 & 58 & 1.69 \\
$\mathrm{~V} / \mathrm{TiO}_{2}$ & 360 & 178 & 50 & 1.99 \\
$\mathrm{~V} / \mathrm{ZrO}_{2}$ & 320 & 175 & 59 & 1.79 \\
\hline
\end{tabular}

be ascribed to, for instance, structural factors $(24,34)$ and to the different type of active sites present on this catalyst (25). The larger selectivity of $\mathrm{V} / \mathrm{TiO}_{2}$ in relation to its reducibility may also be connected with the fact that $\mathrm{TiO}_{2}$ is the only support which shows selectivity to formaldehyde when no vanadia is present. As yet no conclusive explanation can be given for this discrepancy.

\section{c. Consecutive Oxidation of}

Formaldehyde to $\mathrm{CO}$

From Figs. 2-6 it is evident that formaldehyde (and dimethyl ether) production falls sharply owing to a steep rise in formation of $\mathrm{CO}$ with increasing temperature. This points to a consecutive oxidation of formaldehyde to carbon monoxide, which may proceed via formic acid as an intermediate. Because formic acid was never detected in our experiments it is either not an intermediate or it decomposes rapidly to CO (35).

\section{d. Consecutive Oxidation of $\mathrm{CO}$ to $\mathrm{CO}_{2}$}

From Figs. 2-6 it can be seen that at higher temperatures $\mathrm{CO}_{2}$ is formed at the expense of $\mathrm{CO}$. Thus it is plausible to suppose that $\mathrm{CO}$ is consecutively oxidized to $\mathrm{CO}_{2}$. In Fig. 7 the selectivities to $\mathrm{CO}_{2}$ for the methanol oxidation over the supported monolayer catalysts are presented together with the activities for the oxidation of $\mathrm{CO}$ to $\mathrm{CO}_{2}$ obtained in a previous study (25).
This figure shows that the temperatures at which the formation of $\mathrm{CO}_{2}$ in methanol oxidation starts to increase are close to those at which $\mathrm{CO}$ alone starts to be oxidized to $\mathrm{CO}_{2}$ (25). This holds especially for $\mathrm{V} / \gamma-\mathrm{Al}_{2} \mathrm{O}_{3}$ and for $\mathrm{V} / \mathrm{ZrO}_{2}$. For $\mathrm{V} / \mathrm{CeO}_{2}$ and $\mathrm{V} / \mathrm{TiO}_{2}$ the former temperatures are somewhat lower than the latter. In the previous study (25) it was also observed that $\mathrm{V} / \mathrm{CeO}_{2}$ and $\mathrm{V} / \mathrm{TiO}_{2}$ exhibited higher activity for $\mathrm{CO}$ oxidation after reduction by $\mathrm{H}_{2}$ and subsequent reoxidation by $\mathrm{O}_{2}$. On

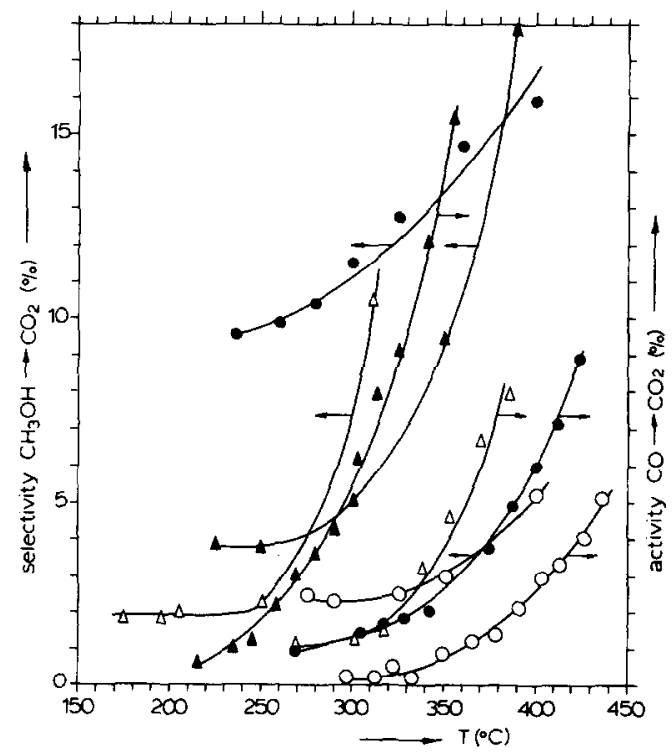

FIG. 7. Selectivity to $\mathrm{CO}_{2}$ for methanol oxidation and activity for $\mathrm{CO}$ oxidation to $\mathrm{CO}_{2}$ over $\mathrm{V} / \gamma-\mathrm{Al}_{2} \mathrm{O}_{3}(\mathrm{O})$, $\mathrm{V} / \mathrm{CeO}_{2}(\odot), \mathrm{V} / \mathrm{TiO}_{2}(\triangle)$, and $\mathrm{V} / \mathrm{ZrO}_{2}(\Delta)$, plotted vs temperature $\left({ }^{\circ} \mathrm{C}\right)$. 
the other hand $\mathrm{V} / \gamma-\mathrm{Al}_{2} \mathrm{O}_{3}$ and $\mathrm{V} / \mathrm{ZrO}_{2}$ were insensitive for reduction/reoxidation treatment.

This seems to be also valid for methanol oxidation: the reduction/reoxidation is then caused by the methanol/oxygen gas mixture, thus creating vacancies and active sites prior to consecutive oxidation to $\mathrm{CO}_{2}$.

In conclusion it may be supposed that at higher temperatures $\mathrm{CO}_{2}$ is formed from produced $\mathrm{CO}$ via a reduction-reoxidation mechanism.

\section{CONCLUSIONS}

On supported and unsupported vanadia the catalytic oxidation of methanol takes place in two stages: ( $l$ ) at moderate temperatures methanol is both dehydrated to dimethyl ether and selectivity oxidized to formaldehyde; (2) at higher temperatures consecutive oxidation of the initial reaction products (ether and formaldehyde) to $\mathrm{CO}$ and consecutive oxidation of $\mathrm{CO}$ to $\mathrm{CO}_{2}$ proceeds.

In general, the selectivity to formaldehyde increases with decreasing reducibility of the catalyst $\left(\mathrm{V} / \mathrm{TiO}_{2}\right.$ being exceptional); this is a function of catalyst-support interactions and can be related to the $z / a$ ratio of the carrier cation.

\section{ACKNOWLEDGMENTS}

Thanks are due to Mr. E. Bijsterbosch and Miss. M. Jovaśević for performing part of the experimental work. Professor J. W. Geus, University of Utrecht, the Netherlands, is acknowledged for his comments on the manuscript.

P.D.C. wishes to thank IAESTE for financial support. This study was supported by the Netherlands Foundation for Chemical Research (SON) with financial aid from the Netherlands Organization for the Advancement of Pure Research (ZWO).

\section{REFERENCES}

I. Walker, J. F., "Formaldehyde," p. 489. Reinhold, New York, 1964.

2. Adkins, H., and Peterson, W. R., J. Amer. Chem. Soc. 53, 1512 (1931).
3. Pernicone, N., J. Less Common Metals 36, 289 (1974).

4. Trifiro, F., and Pasquon, I., J. Catal. 12, 412 (1968).

5. Trifirò, F., Centola, P., and Pasquon, I., $J . C a_{-}$ tal. 10, 86 (1968).

b. Trifirò, F., and Pasquon, I., Chem. Ind. (Milan) 53, 577 (1971).

7. Trifirò, F., Notarbartolo, S., and Pasquon, I., $J$. Catal. 22, 324 (1971).

8. Trifirò, F., De Vecchi, V., and Pasquon, I., J. Catal. 15, 8 (1969).

9. Pernicone, N., Lazzerin, F., Liberti, G., and Lanzavecchia, G., J. Catal. 14, 293, 391 (1969).

10. Jirů, P., Wichterlova, B., Krivánek, M., and Nováková, J., J. Catal. 11, 182 (1968).

11. Pernicone, N., Liberti, G., and Ersini, L., in "Proceedings, 4th International Congress on Catalysis, Moscow, 1968," Vol. 1, p. 287. Akad. Kiado, Budapest, 1971.

12. Nováková, J., Jirů, P., and Zavadil, V., J. Catal. 21, 143 (1971).

13. Sala, F., and Trifirò, F., J. Catal. 41, 1 (1976).

14. Boreskov, G. K., Discuss. Faraday Soc. 41, 263 (1966).

15. Boreskov, G, K., Kinet. Katal. 14, 7 (1973).

16. Ai, M., J. Catal. 54, 426 (1978).

17. Tarama, K., Teranishi, S., Yoshida, S., and Tamura, N., in "Proceedings, 3rd International Congress on Catalysis, Amsterdam, 1964," p. 282. North-Holland, Amsterdam, 1965.

18. Malinski, R., Akimoto, M., and Echigoya, E., J. Catal. 44, 101 (1976).

19. Bhattacharyya, S. K., Janakiram, K., and Ganguly, N. D., J. Catal. 8, 128 (1967).

20. Mann, R. S., and Dosi, M. K., J. Catal. 28, 282 (1973).

21. Agarwal, D. C., Nigam, P. C., and Srivastava, R. D., J. Catal. 55, 1 (1978).

22. Roozeboom, F., Fransen, T., Mars, P., and Gellings, P. J., Z. Anorg. Alkg. Chem. 449, 25 (1979).

23. Roozeboom, F., Medema, J., and Gellings, P. J., Z. Phys. Chem. N. F. 111, 215 (1978).

24. Roozeboom, F., Mittelmeijer-Hazeleger, M. C., Moulijn, J. A., Medema, J., de Beer, V. H. J., and Gellings, P. J., J. Phys. Chem. 84, 2783 (1980).

25. Roozeboom, F., Van Dillen, A. J., Geus, J. W. and Gellings, P. J., in press.

26. Van Willigen, J. H. H. G., Kruidhof, H., and Dahmen, E. A. M. F., Talanta 18, 450 (1971).

27. Winfield, M. E., in "Catalysis" (P. H. Emmett, Ed.), Vol. 7, p. 93. Reinhold, New York, 1960.

28. Pines, H., and Mảnassen, J., in "Advances in Catalysis and Related Subjects," Academic Press, New York/London, 1966. Vol. 16, p. 49.

29. Miyata, H., Wakamiya, M., and Kubokawa, Y., J. Catal. 34, 117 (1974). 
30. Sachtler, W. M. H., Dorgelo, G. J. H., Fahrenfort, J., and Voorhoeve, R. J. H., in 'Proceedings, 4th International Congress on Catalysis, Moscow, 1968," Vol. 1, p. 439. Akad. Kiado, Budapest, 1971.

31. Boreskov, G. K., Kinet. Katal. 14, 7 (1973).

32. Fransen, T., "Molybdenum Oxide Monolayer
Catalysts," Ph.D. thesis. Twente University of Technology, Enschede, The Netherlands, 1977.

33. Fransen, T., Mars, P., and Gellings, P. J., J. Colloid Interface Sci. 70, 97 (1979).

34. Véjux, A., and Courtine, P.,J. Solid State Chem. 23, 93 (1978).

35. Ai. M., J. Catal. 50, 291 (1977). 